\title{
Consumptions of plain water, moisture in foods and beverages, and total water in relation to dietary micronutrient intakes and serum nutrient profiles among US adults
}

\author{
Meng Yang and Ock K Chun* \\ Department of Nutritional Sciences, University of Connecticut, 3624 Horsebarn Road, Extension Unit 4017, \\ Storrs, CT 06269-4017, USA
}

Submitted 20 August 2013: Final revision received 22 November 2013: Accepted 13 January 2014: First published online 10 February 2014

\begin{abstract}
Objective: To investigate water contributors in relation to dietary and serum micronutrient profiles.

Design: A cross-sectional study. The main exposures were water contributors. Selected dietary and serum micronutrient levels were outcome measures.

Settings: The US population and its subgroups.

Subjects: US adults ( $n$ 2691) aged $\geq 20$ years from the National Health and Nutrition Examination Survey 2005-2006.

Results: The daily mean total water intake was $3 \cdot 1$ (se $0 \cdot 047$ ) litres, with $68 \%$ of adults consuming below the Adequate Intake level. Total water intake was higher in adults with higher BMI and physical activity, those taking dietary supplements and alcohol consumers $(P<0 \cdot 05)$. Plain water intake was positively associated with food moisture and negatively with beverage moisture $(P<0 \cdot 001)$. Beverage moisture was negatively associated with food moisture $(P<0 \cdot 001)$. In multivariate regression analyses, plain water and food moisture intakes were positively associated with Fe, Ca, vitamins $\mathrm{A}, \mathrm{B}, \mathrm{C}, \mathrm{E}$ and $\mathrm{K}$ and carotenoid intakes $(P<0 \cdot 05)$. However, beverage moisture was unrelated to $\mathrm{Ca}$, niacin and vitamin $\mathrm{B}_{6}$ intakes, and negatively associated with Fe, vitamin $\mathrm{A}$, folate, vitamins $\mathrm{C}, \mathrm{E}$ and $\mathrm{K}$ and carotenoid intakes $(P<0 \cdot 05)$. Concentrations of serum vitamins $\mathrm{A}$ and $\mathrm{C}$ and carotenoids increased with plain water and food moisture intakes $(P<0.05)$ but decreased $(P<0 \cdot 01)$ or were unrelated to beverage moisture intake.

Conclusions: Various contributors of total water intake differed in their associations with dietary and serum micronutrient profiles in US adults. The study provides evidence of plain water benefits on micronutrient adequacy over beverages.
\end{abstract}

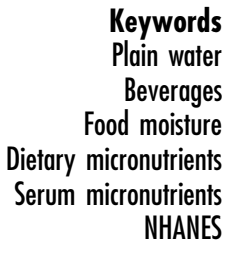

Keywords

Plain water

Beverages

micronutrients

NHANES
Drinking water is essential for supporting life ${ }^{(1)}$ and is a zero-energy, thirst-quenching option when substituting for sugar-sweetened beverages. Water is one of most important nutrients and comprises $75 \%$ of body weight in infants and about $55 \%$ in the elderly ${ }^{(2,3)}$. Nationally representative estimates of total water intake including plain water and moisture in beverages and foods were used for the Dietary Reference Intakes of total water in the $\mathrm{USA}^{(4)}$. The Adequate Intake (AI) of total water for the US population was established in 2004 based on the median total water intake from the Third National Health and Nutrition Examination Survey (NHANES), 1988-1994 ${ }^{(4)}$. The AI for adults over 19 years old is $2 \cdot 7$ and 3.7 litres (2700 and $3700 \mathrm{~g}$, respectively) for women and men, respectively ${ }^{(4)}$.

In addition to the studies considering water as a vehicle for water-borne nutrients ${ }^{(3,5)}$, there has been a large and growing body of literature investigating plain water as a substitution for sugar-sweetened beverages ${ }^{(6-9)}$. Daniel et $a l^{(10)}$ systematically summarized clinical and epidemiological studies suggesting increasing water consumption as an important strategy in reducing energy intake, and consequently preventing obesity, and underscored that the essential fluid which carries many nutrients has been under-studied. Moreover, although several studies have investigated nutritional correlates of beverages ${ }^{(11-13)}$, the association of water consumption with diet quality, especially micronutrient adequacy, is a fairly new focus. Kant et $a l^{(14,15)}$ reported the differential associations of water intake in American adults and adolescents with several dietary nutrient profiles; however, most are energy-related (e.g. fat, carbohydrate, sugars or alcohol). Given the increasing interest in substituting plain water for sugarsweetened beverages to promote health, understanding the association between plain water intake, dietary intake and serum concentration of key vitamins and minerals may help 
emphasize the importance of water. Thus, the present novel study aimed to investigate the associations between water consumption and dietary and serum micronutrient profiles among free-living US adults.

\section{Participants and methods}

\section{Study population}

The NHANES conducted by the National Center for Health Statistics at the Centers for Disease Control and Prevention obtains nationally representative information on the health and nutritional status of the US population. Participants were interviewed and had blood samples taken in the mobile examination centre where the first $24 \mathrm{~h}$ dietary recall ${ }^{(16)}$ (midnight to midnight) and questionnaires on dietary supplement use were administered. The day 2 recall was conducted by telephone interview approximately 3-10 d after the day 1 recall. Individuals aged 20 years and older in NHANES 2005-2006 ${ }^{(17)}$, having reliable and complete $2 \mathrm{~d}$ dietary recall data and serum nutrient data, were included in the present study ${ }^{(18)}$. NHANES 2005-2006 data set was chosen because it was the most current cycle with relatively complete data on the variables related to water intake such as physical activity. Participants were grouped by sociodemographic and behavioural variables to examine water intake: age (20-30, 31-50, 51-70, >70 years), sex, ethnicity (nonHispanic White; non-Hispanic Black; Mexican-American; Others), BMI $(<18 \cdot 5, \geq 18 \cdot 5$ to $<25 \cdot 0, \geq 25 \cdot 0$ to $<30 \cdot 0$, $\left.\geq 30 \cdot 0 \mathrm{~kg} / \mathrm{m}^{2}\right)$, years of education $(<12,12,>12$ years $)$, alcohol consumption (yes or no to 'at least 12 drinks/year'), current smoking (yes or no to 'current smoking' and 'smoked cigarettes, cigars, or pipes and/or used chewing tobacco or snuff at least once during the past $30 \mathrm{~d}$ '), dietary supplement use (yes or no), income-poverty ratio $(<1 \cdot 0$, $1 \cdot 0-1 \cdot 3,1 \cdot 3-1 \cdot 85, \geq 1 \cdot 85)$ and exercise levels. Incomepoverty ratio was calculated by dividing family income by the poverty guidelines and acts as a variable of socioeconomic status. An income-poverty ratio of $<1 \cdot 3$ is required to be eligible for food assistance programmes. The exercise levels were expressed as the metabolic equivalent (MET) score calculated by combining the intensity level of the leisure-time activities reported, mean duration and frequency. Written informed consent was obtained from all participants or proxies, and the survey protocol was approved by the Research Ethics Review Board of the National Center for Health Statistics.

\section{Estimation of water intake}

Total water intake was provided in NHANES 2005-2006 and based on plain water, moisture in beverages and moisture in foods. Plain water variable was also provided in the data set and defined by the National Center for Health Statistics to include plain tap water, water from a drinking fountain, water from a water cooler, bottled water and spring water. Moisture in beverages included a variety of liquids, such as milk, hot chocolate, coffee, tea, fruit and vegetable juices, juice drinks, carbonated and non-carbonated sweetened or unsweetened drinks, alcoholic drinks and others such as carbonated water, vitamin water, sports drinks and energy drinks. Moisture in foods was obtained by subtracting plain water and moisture in beverages from total water. Additionally, the adequacy of total water intake was determined by comparing intake from the averaged non-consecutive two $24 \mathrm{~h}$ dietary recalls to the $\mathrm{AI}^{(19)}$. Estimates were generated for percentages of individuals below the AI for total water intake ${ }^{(4)}$.

\section{Dietary micronutrient variables}

The dietary intake data were estimated from $24 \mathrm{~h}$ dietary recall interviews conducted in the NHANES 2005-2006 ${ }^{(17)}$. Dietary recalls were conducted by trained interviewers using the US Department of Agriculture's Automated Multiple Pass Method ${ }^{(20)}$. Food consumption data were coded using the US Department of Agriculture's Food and Nutrient Database for Dietary Studies $3 \cdot 0$ to produce nutrient intake values for minerals ( $\mathrm{Fe}$ and $\mathrm{Ca}$ ), vitamins (vitamin $\mathrm{A}$, vitamin $\mathrm{C}$, vitamin $\mathrm{E}$, vitamin $\mathrm{K}$, thiamin, riboflavin, niacin, vitamin $\mathrm{B}_{6}$ and folate) and carotenoids $(\alpha$-carotene, $\beta$-carotene, $\beta$-cryptoxanthin, lycopene and lutein + zeathanthin).

\section{Serum micronutrient variables}

Specimen collection and processing were carried out according to the NHANES Laboratory/Medical Technologists Procedures Manual ${ }^{(21)}$. Serum Fe concentration was measured by a timed-endpoint method through reducing $\mathrm{Fe}^{3+}$ released from transferrin to the $\mathrm{Fe}^{2+}$ state ${ }^{(22)}$. Indirect ion-selective electrode methodology by the LX20 system was used to measure Ca levels in serum ${ }^{(23)}$. Serum concentrations of vitamin A, vitamin $\mathrm{C}$, vitamin $\mathrm{E}$ $(\alpha$-tocopherol) and six carotenoids $(\beta$-cryptoxanthin, trans-lycopene, $\alpha$-carotene, trans- $\beta$-carotene, cis- $\beta$-carotene, cis-combined lutein/zeaxanthin) were measured using HPLC with multi-wavelength photodiode-array absorbance detection $^{(24,25)}$. Serum was mixed with meta-phosphoric acid to acidify the serum and stabilize ascorbate before measurement of vitamin $\mathrm{C}$ status ${ }^{(21)}$. Vitamin $\mathrm{B}_{12}$ was measured by using the Bio-Rad Laboratories 'Quantaphase II Folate/Vitamin $\mathrm{B}_{12}$ ' radioassay kit ${ }^{(26)}$. The $\mathrm{CV}$ for $\mathrm{Fe}, \mathrm{Ca}$, vitamin $\mathrm{A}$, vitamin $\mathrm{E}$ and $\beta$-carotene were generally less than $5 \%{ }^{(25)}$. The $\mathrm{CV}$ for vitamin $\mathrm{C}$ were in the range of $<10 \%$ and for the minor carotenoids were generally less than $20 \%{ }^{(25)}$. For vitamin $\mathrm{B}_{12}$, the $\mathrm{CV}$ was $5-7 \%$ at $300-1500 \mathrm{pg} / \mathrm{ml}$ and $5-6 \%$ at $200 \mathrm{pg} / \mathrm{ml}^{(26)}$.

\section{Statistical analysis}

All data analyses were carried out using the SAS statistical software package, version 9.2 (2009). Sample weights were applied to all analyses to account for the unequal 
probability of selection, non-coverage and non-response bias resulting from oversampling of low-income persons, adolescents, the elderly, African-Americans and MexicanAmericans.

Arithmetic means of micronutrient intakes of subpopulations grouped by sociodemographic and lifestyle variables were determined. Standard errors were calculated by the linearization (Taylor series) variance estimation method for population parameters. All the variables were log-transformed to approximate normality. ANOVA was used to compare water intakes according to different sociodemographic and lifestyle groups controlling for covariates. Physical activity expressed as MET score was divided as 0 and tertiles of MET (T1, T2 and T3). Associations between water contributors and dietary micronutrient intakes were tested using multiple linear regression analyses considering each dietary micronutrient intake as a dependent variable after adjusting for relevant covariates. The covariates include total energy intake, age, sex, race/ethnicity, BMI, income-poverty ratio, years of education, physical activity, alcohol consumption, current smoking status, dietary supplement intake and any selfreported chronic disease. Multiple linear regression analyses were also used to examine the relationship between water contributors and serum micronutrient concentrations adjusting for the aforementioned covariates. Associations are presented as regression coefficients and their standard errors to reflect the predicted change of dietary or serum micronutrient levels given a unit increase in reported water intake. All $P$ values were two-tailed and statistical significance was defined as $P<0 \cdot 05$.

\section{Results}

The daily mean total water intake was $3066 \mathrm{~g}$ (3.1 litres) with about $68 \%$ of the population consuming less than the AI (Table 1). Beverages accounted for $46 \%$ of total water intake followed by plain water (32\%) and moisture in foods $(22 \%)$. Total water intake was higher in men, individuals aged 31-50 years old, non-Hispanic Whites and in participants who had higher education levels than their counterparts $(P<0 \cdot 0001)$. Higher BMI and physical activity were associated with more total water intake $(P<0 \cdot 05)$. Alcohol consumers, current smokers and dietary supplement users consumed more water than their counterparts $(P<0 \cdot 01)$. Similar associations were found between different water contributors and the aforementioned sociodemographic and behavioural factors (Table 1).

Plain water, moisture in beverages and moisture in foods were positively associated with total water intake after adjusting for covariates (Table 2). Plain water was positively associated with moisture in foods and negatively associated with moisture in beverages. Moisture in beverages was negatively associated with moisture in foods $(P<0 \cdot 0001)$. Associations between water contributors and dietary micronutrients are shown in Table 3. Total water intake was positively associated with dietary micronutrients such as $\mathrm{Ca}$, vitamin $\mathrm{A}, \mathrm{B}$ vitamins (thiamin, riboflavin and folate), vitamin $\mathrm{C}$, vitamin $\mathrm{E}$, vitamin $\mathrm{K}$ and carotenoids ( $\alpha$-carotene, $\beta$-carotene, $\beta$-cryptoxanthin, lycopene and lutein + zeathanthin; $P<0 \cdot 01$ ). When examining the associations between water contributors and dietary micronutrients, plain water showed the same trend as total water intake and was positively associated with most essential dietary minerals, vitamins and carotenoids $(P<0 \cdot 05)$. Moisture in foods was a positive correlate of all the dietary micronutrients $(P<0 \cdot 001)$. However, water intake from beverages was negatively associated with dietary $\mathrm{Fe}$, vitamin A, several B vitamins, vitamin $\mathrm{C}$, vitamin $\mathrm{E}$, vitamin $\mathrm{K}$ and carotenoids $(P<0 \cdot 05)$.

Table 4 shows the associations between water contributors and serum micronutrient levels. Total water intake was positively associated with serum essential micronutrients such as $\mathrm{Ca}$, vitamin $\mathrm{A}$, vitamin $\mathrm{E}$ and several carotenoids ( $\alpha$-carotene, trans- $\beta$-carotene, cis- $\beta$-carotene and lutein + zeathanthin; $P<0.05$ ). Plain water and moisture in foods were positively correlated with most serum micronutrient concentrations $(P<0 \cdot 05)$. However, increased moisture in beverages was associated with a decrease in several serum micronutrient levels $(P<0 \cdot 01)$.

\section{Discussion}

The present study documented a positive association of total water, plain water and moisture in foods with dietary and serum minerals, vitamins and carotenoids, but a negative correlation of moisture in beverages with several essential nutrient intakes and serum levels. This may imply the diverse impact of water sources on dietary and serum micronutrient profiles, providing a different perspective for water benefits from its possible displacement of energy from sugar-sweetened beverages.

Mean water intakes across various sociodemographic characteristics were comparable to those in Kant et al.'s study ${ }^{(14)}$. Plain water intake was associated with several indicators of healthy lifestyles, such as high physical activity and regularly taking dietary supplements. Our results also underscored a significant contribution from food moisture. According to the US Department of Agriculture, the top food items having plentiful water content include fruits and vegetables, while the least 'water' foods are oils, sugars, nuts, snacks, butter and cakes $^{(27)}$. Therefore, higher food moisture intake probably implied higher consumption of fruits and vegetables. Additionally, dietary supplement users tended to drink more plain water and have more moisture-abundant food items. Although large percentages of US adults consumed total water less than the AI for water based on dietary data, it is impossible to assess the adequacy of water intake among the US population because there is no 
Table 1 Comparisons of water intake from plain water, moisture in beverages and moisture in foods by sociodemographic and behavioural characteristics among US adults aged $\geq 20$ years in NHANES 2005-2006 $(n 2691)^{\star}, \dagger$

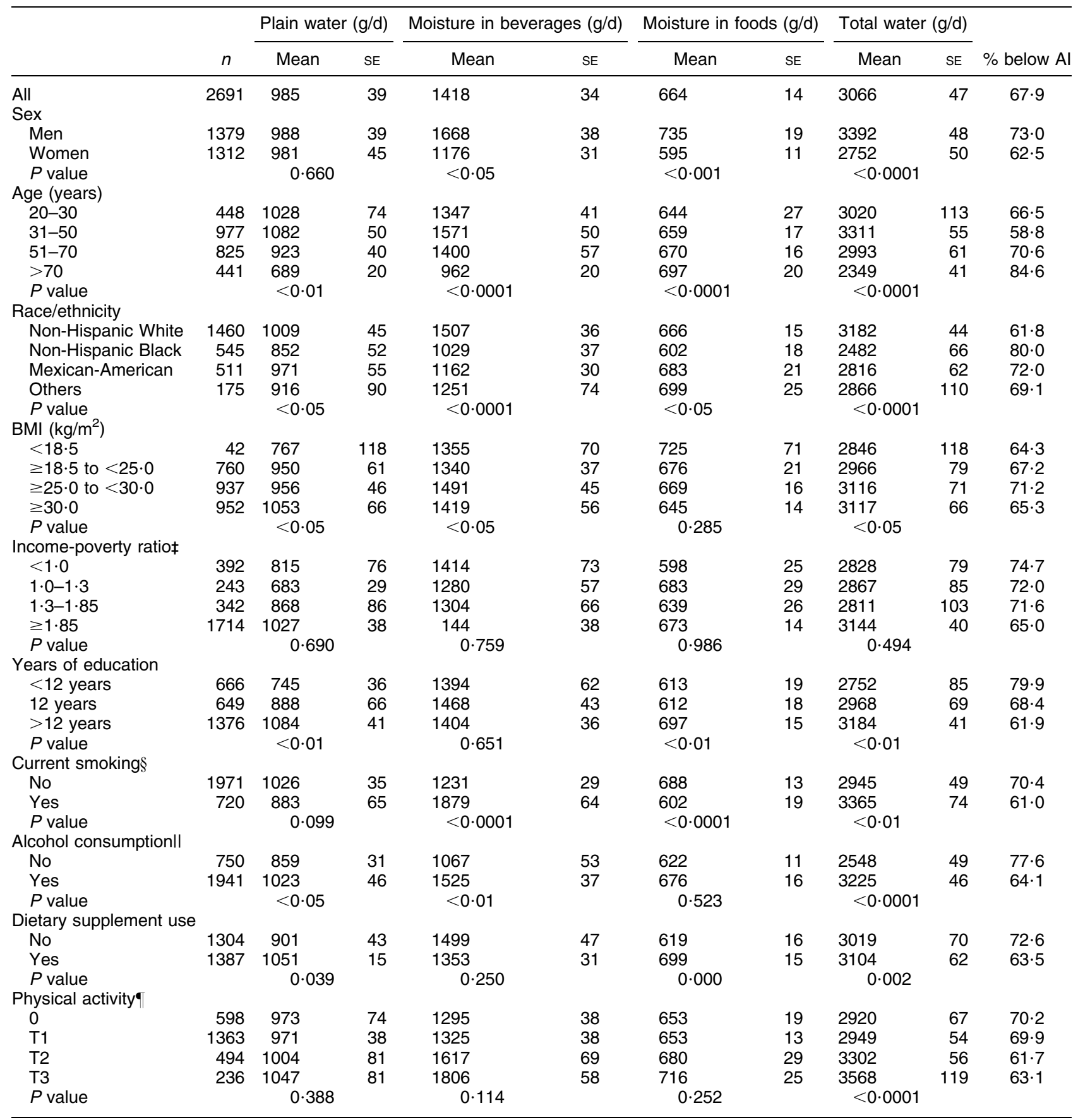

NHANES, National Health and Nutrition Examination Survey; Al, Adequate Intake; MET, metabolic equivalent.

*Water intakes were estimated based on the two $24 \mathrm{~h}$ dietary recalls in NHANES 2005-2006. Total water was a combination of plain water, moisture in beverages and moisture in foods.

tAll values are means with their standard errors. $P$ value was obtained by ANOVA controlling for the covariates listed in the table.

¥Ratio of the median family income to the poverty index. An income-poverty ratio $\leq 1 \cdot 30$ is required to be eligible for food assistance programmes.

$\S$ Current smoking: yes means to have smoked cigarettes, cigars or pipes, or to have used chewing tobacco or snuff at least once during the past $30 \mathrm{~d}$.

IIAlcohol consumption: yes means to consume $\geq 12$ alcoholic beverages/year.

$\uparrow$ Exercise levels, expressed as the MET score, were calculated by combining the intensity level of the leisure-time activities reported, mean duration and frequency.

accepted method or completely adequate biomarkers to assess hydration status at the population level ${ }^{(4,28,29)}$. Thereby, as suggested by Popkin et al. ${ }^{(29)}$, incomplete data and validation approaches for evaluating water requirements are at best suggestive of an issue deserving extensive exploration.

Our results suggested differential associations between water contributors and dietary micronutrient intakes. 
Table 2 Associations among total water, plain water, moisture in beverages and moisture in foods among US adults aged $\geq 20$ years in NHANES 2005-2006 $(n \text { 2691 })^{\star},+$

\begin{tabular}{|c|c|c|c|c|c|c|c|c|}
\hline & \multicolumn{2}{|c|}{ Total water } & \multicolumn{2}{|c|}{ Plain water } & \multicolumn{2}{|c|}{ Moisture in beverages } & \multicolumn{2}{|c|}{ Moisture in foods } \\
\hline & $\beta$ & $P$ value & $\beta$ & $P$ value & $\beta$ & $P$ value & $\beta$ & $P$ value \\
\hline $\begin{array}{l}\text { Plain water } \\
\text { Moisture in beverages } \\
\text { Moisture in foods }\end{array}$ & $\begin{array}{l}0 \cdot 23 \\
0 \cdot 22 \\
0 \cdot 18\end{array}$ & $\begin{array}{l}<0.0001 \\
<0.0001 \\
<0.0001\end{array}$ & - & - & $-0 \cdot 10$ & $<0.0001$ & $\begin{array}{r}0.06 \\
-0.32\end{array}$ & $\begin{array}{l}<0.0001 \\
<0.0001\end{array}$ \\
\hline
\end{tabular}

NHANES, National Health and Nutrition Examination Survey.

*Water intakes were estimated based on the two $24 \mathrm{~h}$ dietary recalls in NHANES 2005-2006. Total water was a combination of plain water, moisture in beverages and moisture in foods.

tThe multiple linear regression models were adjusted for age, race/ethnicity, sex, BMI, income-poverty ratio, years of education, smoking status, alcohol intake, dietary supplement intake, physical activity, chronic disease incidence and energy intake.

Table 3 Associations of water contributors and total water intake with micronutrient intake status among US adults aged $\geq 20$ years in NHANES 2005-2006 $(n \text { 2691 })^{*},+$

\begin{tabular}{|c|c|c|c|c|c|c|c|c|c|c|c|c|}
\hline \multirow[b]{2}{*}{ Dietary micronutrient } & \multicolumn{3}{|c|}{ Plain water (g/d) } & \multicolumn{3}{|c|}{ Moisture in beverages $(\mathrm{g} / \mathrm{d})$} & \multicolumn{3}{|c|}{ Moisture in foods (g/d) } & \multicolumn{3}{|c|}{ Total water (g/d) } \\
\hline & $\beta$ & SE & $P$ value & $\beta$ & SE & $P$ value & $\beta$ & SE & $P$ value & $\beta$ & SE & $P$ value \\
\hline $\mathrm{Fe}(\mathrm{mg} / \mathrm{d})$ & 0.01 & 0.01 & $0 \cdot 103$ & -0.07 & 0.02 & $<0.01$ & $0 \cdot 18$ & 0.02 & $<0.0001$ & 0.03 & 0.02 & 0.077 \\
\hline $\mathrm{Ca}(\mathrm{mg} / \mathrm{d})$ & 0.09 & 0.01 & $<0.0001$ & -0.02 & 0.02 & 0.301 & $0 \cdot 12$ & 0.02 & $<0.0001$ & 0.25 & 0.02 & $<0.0001$ \\
\hline Vitamin A $(\mu \mathrm{g} / \mathrm{d})$ & 0.06 & 0.01 & $<0.0001$ & $-0 \cdot 11$ & 0.03 & $<0.01$ & 0.48 & 0.04 & $<0.0001$ & 0.20 & 0.03 & $<0.0001$ \\
\hline \multicolumn{13}{|l|}{ Vitamin B } \\
\hline Thiamin (mg/d) & 0.03 & 0.01 & $<0.05$ & 0.07 & 0.02 & $<0.05$ & $0 \cdot 13$ & 0.03 & $<0.001$ & $0 \cdot 19$ & 0.02 & $<0.0001$ \\
\hline Riboflavin (mg/d) & 0.03 & 0.01 & $<0.05$ & $0 \cdot 11$ & 0.02 & $<0.001$ & 0.07 & 0.01 & $<0.001$ & 0.23 & 0.02 & $<0.0001$ \\
\hline Niacin $(\mathrm{mg} / \mathrm{d})$ & 0.04 & 0.01 & $<0.01$ & 0.00 & 0.02 & 0.885 & $0 \cdot 17$ & 0.03 & $<0.0001$ & $0 \cdot 16$ & 0.02 & $<0.0001$ \\
\hline Folate ( $\mu \mathrm{g}$ DFE/d) & 0.03 & 0.01 & $<0.01$ & -0.05 & 0.02 & $<0.05$ & $0 \cdot 25$ & 0.03 & $<0.0001$ & $0 \cdot 16$ & 0.03 & $<0.0001$ \\
\hline Vitamin $B_{6}(\mathrm{mg} / \mathrm{d})$ & 0.05 & 0.01 & $<0.01$ & -0.02 & 0.03 & 0.489 & 0.30 & 0.03 & $<0.0001$ & 0.23 & 0.02 & $<0.0001$ \\
\hline Vitamin $C(\mathrm{mg} / \mathrm{d})$ & 0.09 & 0.02 & $<0.01$ & -0.23 & 0.03 & $<0.0001$ & $1 \cdot 26$ & 0.05 & $<0.0001$ & 0.38 & 0.05 & $<0.0001$ \\
\hline Vitamin $E(\mathrm{mg} / \mathrm{d}) \ddagger$ & 0.03 & 0.01 & $<0.01$ & $-0 \cdot 10$ & 0.02 & $<0.01$ & $0 \cdot 32$ & 0.03 & $<0.0001$ & 0.09 & 0.02 & $<0.01$ \\
\hline Vitamin $K(\mu \mathrm{g} / \mathrm{d})$ & 0.06 & 0.02 & $<0.05$ & $-0 \cdot 16$ & 0.03 & $<0.0001$ & $0 \cdot 74$ & 0.05 & $<0.0001$ & 0.27 & 0.06 & $<0.001$ \\
\hline \multicolumn{13}{|l|}{ Carotenoids } \\
\hline$\alpha$-Carotene $(\mu \mathrm{g} / \mathrm{d})$ & $0 \cdot 16$ & 0.06 & $<0.05$ & -0.32 & 0.09 & $<0.01$ & $1 \cdot 86$ & 0.07 & $<0.0001$ & $0 \cdot 80$ & $0 \cdot 12$ & $<0.0001$ \\
\hline$\beta$-Carotene $(\mu \mathrm{g} / \mathrm{d})$ & $0 \cdot 13$ & 0.02 & $<0.001$ & -0.28 & 0.06 & $<0.001$ & 1.52 & 0.04 & $<0.0001$ & 0.60 & 0.05 & $<0.0001$ \\
\hline$\beta$-Cryptoxanthin $(\mu \mathrm{g} / \mathrm{d})$ & $0 \cdot 10$ & 0.04 & $<0.05$ & -0.37 & 0.04 & $<0.0001$ & $1 \cdot 85$ & 0.08 & $<0.0001$ & 0.45 & $0 \cdot 12$ & $<0.01$ \\
\hline Lycopene $(\mu \mathrm{g} / \mathrm{d})$ & $0 \cdot 16$ & 0.03 & $<0.001$ & $-0 \cdot 30$ & 0.07 & $<0.001$ & $0 \cdot 70$ & 0.09 & $<0.0001$ & 0.28 & 0.08 & $<0.01$ \\
\hline Lutein + zeathanthin $(\mu \mathrm{g} / \mathrm{d})$ & $0 \cdot 11$ & 0.03 & $<0.001$ & -0.23 & 0.03 & $<0.0001$ & $1 \cdot 19$ & 0.05 & $<0.0001$ & 0.48 & 0.06 & $<0.0001$ \\
\hline
\end{tabular}

NHANES, National Health and Nutrition Examination Survey; DFE, dietary folate equivalents.

*Water and dietary micronutrient intakes were estimated based on the two $24 \mathrm{~h}$ dietary recalls in NHANES 2005-2006. Total water was a combination of plain water, moisture in beverages and moisture in foods.

tAll values are $\beta$ coefficients and their standard errors. $P$ value was estimated from multiple linear regression model. The multiple linear regression considers each dietary micronutrient intake as a dependent variable and water contributors as independent variables after adjusting for total energy intake, age, sex, race/ethnicity, BMI, income-poverty ratio, years of education, physical activity, alcohol consumption, current smoking status, dietary supplement intake and any self-reported chronic disease. All the missing values on any variables were excluded.

$\ddagger$ Vitamin E estimate included $\alpha$-tocopherol intake only.

Moisture in foods was the water source which had the most positive association with the dietary micronutrients and was the largest factor that influenced total water effect on dietary nutrient profiles. In contrast, beverages, the top contributor to total water intake, was inversely associated with nutrient profiles and ameliorated the effect of total water on dietary nutrient profiles. Interestingly, plain water, absent of any examined micronutrients itself, served as a positive correlate. These discrepancies might be partially explained by the correlations among these water contributors. The positive association of plain water with food moisture and the inverse association with beverages suggested that plain water affected dietary micronutrients possibly through substituting beverage consumption and improving high-water-content food items such as fruits and vegetables ${ }^{(14,29)}$. In addition, these findings probably stemmed from the dietary patterns each water contributor closely related to. As noted by previous studies ${ }^{(30,31)}$, increased plain water intake was associated with healthier dietary patterns composed of higher consumption of fruits, vegetables, and low- and reduced-fat dairy products; while increased beverage (excluding plain water) consumption was associated with the meal pattern of snacks and high-fat foods. Furthermore, dietary minerals were not affected by water intakes as much as dietary vitamins and carotenoids, which could be explained by the relative lower mineral content in major moisture-abundant food items. Consequently, plain water and food moisture were potential dietary components to be promoted to increase dietary micronutrient profiles; however, the opposite trend was revealed for beverage intake.

Water contributors have demonstrated a similar impact on serum micronutrient concentrations as dietary micronutrient 
Table 4 Associations of water contributors and total water intake with serum micronutrient concentrations among US adults aged $\geq 20$ years in NHANES 2005-2006 $(n 2691)^{\star}, \dagger$

\begin{tabular}{|c|c|c|c|c|c|c|c|c|c|c|c|c|}
\hline \multirow[b]{2}{*}{ Serum micronutrient } & \multicolumn{3}{|c|}{ Plain water $(g / d)$} & \multicolumn{3}{|c|}{ Moisture in beverages $(\mathrm{g} / \mathrm{d})$} & \multicolumn{3}{|c|}{ Moisture in foods $(\mathrm{g} / \mathrm{d})$} & \multicolumn{3}{|c|}{ Total water $(\mathrm{g} / \mathrm{d})$} \\
\hline & $\beta$ & SE & $P$ value & $\beta$ & SE & $P$ value & $\beta$ & SE & $P$ value & $\beta$ & SE & $P$ value \\
\hline $\mathrm{Fe}(\mu \mathrm{g} / \mathrm{dl})$ & 0.020 & 0.012 & $0 \cdot 105$ & 0.021 & $0 \cdot 018$ & 0.255 & 0.002 & 0.028 & 0.942 & 0.046 & 0.026 & 0.096 \\
\hline $\mathrm{Ca}(\mathrm{mg} / \mathrm{dl})$ & 0.003 & 0.001 & $<0.01$ & 0.001 & 0.001 & 0.482 & 0.003 & 0.002 & 0.135 & 0.007 & 0.002 & $<0.01$ \\
\hline Vitamin $A(\mu \mathrm{g} / \mathrm{dl})$ & $0 \cdot 021$ & 0.007 & $<0.01$ & -0.013 & $0 \cdot 013$ & 0.339 & 0.029 & 0.013 & $<0.05$ & 0.067 & $0 \cdot 018$ & $<0.01$ \\
\hline Vitamin $\mathrm{B}_{12}(\mathrm{pg} / \mathrm{ml})$ & 0.030 & 0.010 & $<0.05$ & -0.040 & 0.020 & 0.054 & $0 \cdot 100$ & 0.030 & $<0.01$ & 0.050 & 0.040 & 0.225 \\
\hline Vitamin C (mg/dl) & 0.050 & 0.015 & $<0.01$ & $-0 \cdot 107$ & 0.025 & $<0.001$ & 0.367 & 0.029 & $<0.0001$ & $0 \cdot 106$ & 0.049 & $<0.05$ \\
\hline Vitamin $E(\mu \mathrm{g} / \mathrm{dl}) \ddagger$ & 0.024 & 0.012 & 0.066 & -0.025 & 0.012 & 0.054 & 0.067 & 0.016 & $<0.001$ & 0.063 & 0.029 & $<0.05$ \\
\hline \multicolumn{13}{|l|}{ Carotenoids } \\
\hline$\alpha$-Carotene $(\mu \mathrm{g} / \mathrm{dl})$ & $0 \cdot 051$ & 0.023 & $<0.05$ & $-0 \cdot 162$ & $0 \cdot 041$ & $<0.01$ & $0 \cdot 719$ & 0.054 & $<0.0001$ & 0.273 & 0.060 & $<0.001$ \\
\hline Trans- $\beta$-carotene $(\mu \mathrm{g} / \mathrm{dl})$ & 0.057 & 0.016 & $<0.01$ & $-0 \cdot 141$ & 0.037 & $<0.01$ & 0.563 & 0.060 & $<0.0001$ & 0.225 & 0.052 & $<0.001$ \\
\hline Cis- $\beta$-carotene $(\mu \mathrm{g} / \mathrm{dl})$ & 0.049 & 0.014 & $<0.01$ & -0.096 & 0.021 & $<0.001$ & 0.388 & 0.040 & $<0.0001$ & $0 \cdot 182$ & 0.041 & $<0.001$ \\
\hline$\beta$-Cryptoxanthin $(\mu \mathrm{g} / \mathrm{dl})$ & 0.035 & 0.015 & $<0.05$ & $-0 \cdot 152$ & 0.028 & $<0.0001$ & $0 \cdot 510$ & $0 \cdot 040$ & $<0.0001$ & 0.091 & 0.056 & $0 \cdot 126$ \\
\hline Lycopene $(\mu \mathrm{g} / \mathrm{dl})$ & 0.003 & 0.011 & 0.809 & -0.013 & 0.021 & 0.537 & $0 \cdot 122$ & 0.037 & $<0.01$ & 0.041 & 0.034 & 0.238 \\
\hline Lutein + zeathanthin $(\mu \mathrm{g} / \mathrm{dl})$ & 0.040 & 0.016 & $<0.05$ & -0.084 & 0.021 & $<0.01$ & 0.342 & 0.039 & $<0.0001$ & 0.125 & 0.039 & $<0.01$ \\
\hline
\end{tabular}

NHANES, National Health and Nutrition Examination Survey.

*Water intakes were estimated based on the two $24 \mathrm{~h}$ dietary recalls in NHANES 2005-2006. Total water was a combination of plain water, moisture in beverages and moisture in foods.

tAll values are $\beta$ coefficients and their standard errors. $P$ value was estimated from multiple linear regression model. The multivariate linear regression considers each serum micronutrient concentration as a dependent variable and water contributors as independent variables after adjusting for total energy intake, age, sex, race/ethnicity, BMI, income-poverty ratio, years of education, physical activity, alcohol consumption, current smoking status, dietary supplement intake and any self-reported chronic disease. All the missing values on any variables were excluded.

$\ddagger$ Vitamin $\mathrm{E}$ estimate included $\alpha$-tocopherol concentrations only.

intakes, especially on serum vitamin and carotenoid levels. Since the assumption that consumption of water alone or beverages containing water affects hydration differentially is not validated ${ }^{(4,32)}$, the divergent in vivo effects from water contributors, to a large extent, are dependent on dietary intake alterations. Food moisture was the top contributor to increased serum vitamins and carotenoids followed by plain water intake, while beverages decreased these serum nutrient concentrations. Plasma or serum carotenoids are the most commonly used biomarkers for indicating vegetable, fruit or fruit juice consumption $^{(16,33)}$. Thus, the increased serum carotenoids indicated a positive association between water intake and fruit and vegetable intake, which was consistent with previous studies ${ }^{(30,31)}$. As a result, the findings suggested that promoting plain water or moisture-abundant food items could potentially improve the serum micronutrient status while beverages diminished it.

To our best knowledge, the present study is the first to document dietary and serum nutritional benefits associated with water intake in the US free-living population on a large scale. However, we acknowledge that although two $24 \mathrm{~h}$ dietary recalls were used for dietary intake estimation including water consumption, they are still prone to systematic and random measurement errors and might not be accurately presenting the usual American diet $^{(34)}$. Also, the poorly developed water requirements hindered the further investigation of water adequacy with respect to different sociodemographic and behavioural characteristics. Expression of water requirements relative to energy requirements is suggested with variability by age, sex, body size (or surface area) and physical activity level ${ }^{(29)}$. Moreover, the beverage variable was generated without distinguishing nutritious beverages such as fruit juices, milk and soda, which might mitigate the contributions from beverages on nutrient profiles.

\section{Conclusion}

The present study examined water consumption with a different insight by examining the relevant associations of water contributors on nutrient intakes and serum profiles among US adults. The different associations of dietary and serum micronutrient compositions with various water contributors provide additional evidence to encourage plain water intake over other beverages (e.g. sugar-sweetened beverages) for improving micronutrient adequacy. The differential effects from water contributors on health outcomes, not only obesity, warrant further investigation.

\section{Acknowledgements}

Sources of funding: This present study received no specific grant from any funding agency in the public, commercial or not-for-profit sectors. Conflicts of interest: Both authors have no conflicts of interest to declare. Authors' contributions: O.K.C. developed the concept. O.K.C. and M.Y. constructed the study design. M.Y. conducted the statistical analysis and drafted the manuscript. Both authors were involved in the data interpretation and manuscript preparation. Acknowledgements: The authors would like to thank Dr Sohyun Park from the Division of Nutrition, Physical Activity, and Obesity, Centers for Disease Control and Prevention for guidance and suggestions. 


\section{References}

1. Horswill C \& Janas L (2011) Hydration and health. Am J Lifestyle Med 5, 304-315.

2. Schoeller D (2005) Hydrometry. In Human Body Composition, pp. 35-50 [S Heymsfield, T Lohman, Z Wang et al., editors]. Champaign, IL: Human Kinetics.

3. Sebastian RS, Wilkinson Enns C, Goldman JD et al. (2012) Change in methodology for collection of drinking water intake in What We Eat in America/National Health and Nutrition Examination Survey: implications for analysis. Public Health Nutr 15, 1190-1195.

4. Institute of Medicine, Food and Nutrition Board (2005) Dietary Reference Intakes for Water, Potassium, Sodium, Chloride, and Sulfate. Washington, DC: National Academy Press.

5. Mons MN, van der Wielen JM, Blokker EJ et al. (2007) Estimation of the consumption of cold tap water for microbiological risk assessment: an overview of studies and statistical analysis of data. J Water Health 5, Suppl. 1, 151-170.

6. Dennis EA, Flack KD \& Davy BM (2009) Beverage consumption and adult weight management: a review. Eat Behav 10, 237-246.

7. Pan A, Malik VS, Hao T et al. (2013) Changes in water and beverage intake and long-term weight changes: results from three prospective cohort studies. Int J Obes (Lond) 37, 1378-1385.

8. Tate DF, Turner-McGrievy G, Lyons E et al. (2012) Replacing caloric beverages with water or diet beverages for weight loss in adults: main results of the Choose Healthy Options Consciously Everyday (CHOICE) randomized clinical trial. Am J Clin Nutr 95, 555-563.

9. Stookey JD, Constant F, Gardner CD et al. (2007) Replacing sweetened caloric beverages with drinking water is associated with lower energy intake. Obesity (Silver Spring) 15, 3013-3022

10. Daniels MC \& Popkin BM (2010) Impact of water intake on energy intake and weight status: a systematic review. Nutr Rev 68, 505-521.

11. Harnack L, Stang J \& Story M (1999) Soft drink consumption among US children and adolescents: nutritional consequences. J Am Diet Assoc 99, 436-441.

12. Wang YC, Bleich SN \& Gortmaker SL (2008) Increasing caloric contribution from sugar-sweetened beverages and $100 \%$ fruit juices among US children and adolescents, 1988-2004. Pediatrics 121, 1604-1614.

13. Vartanian LR, Schwartz MB \& Brownell KD (2007) Effects of soft drink consumption on nutrition and health: a systematic review and meta-analysis. Am J Public Health 97, 667-675.

14. Kant AK, Graubard BI \& Atchison EA (2009) Intakes of plain water, moisture in foods and beverages, and total water in the adult US population - nutritional, meal pattern, and body weight correlates: National Health and Nutrition Examination Surveys 1999-2006. Am J Clin Nutr 90, 655-663.

15. Kant AK \& Graubard BI (2010) Contributors of water intake in US children and adolescents: associations with dietary and meal characteristics - National Health and Nutrition Examination Survey 2005-2006. Am J Clin Nutr 92, 887-896.

16. Carlsen MH, Karlsen A, Lillegaard IT et al. (2011) Relative validity of fruit and vegetable intake estimated from an FFQ, using carotenoid and flavonoid biomarkers and the method of triads. Br J Nutr 105, 1530-1538.

17. National Center for Health Statistics (2008) National Health and Nutrition Examination Survey, 2005-2006 Data Files. Hyattsville, MD: Centers for Disease Control and Prevention; available at http://wwwn.cdc.gov/nchs/nhanes/ search/nhanes05_06.aspx
18. National Center for Health Statistics (2008) National Health and Nutrition Examination Survey, 2005-2006 Data Documentation: Dietary Interview-Individual Foods. Hyattsville, MD: Centers for Disease Control and Prevention; available at http://www.cdc.gov/nchs/nhanes/ nhanes2005-2006/DR1IFF_D.htm

19. Institute of Medicine, Food and Nutrition Board (2000) Dietary Reference Intakes: Applications in Dietary Assessment. Washington, DC: National Academy Press.

20. Botman S, Moore T, Moriarity C et al. (2000) Design and estimation for the national health interview survey, 1995-2004. Vital Health Stat 2, issue 130, 1-41.

21. National Center for Health Statistics (2004) General Information for the Public Files of the 2005-2006 Laboratory Data. Hyattsville, MD: Centers for Disease Control and Prevention; available at http://www.cdc.gov/ nchs/data/nhanes/nhanes_05_06/lab_d_generaldoc.pdf

22. Collaborative Laboratory Services (2007) Laboratory Procedure Manual: Iron Concentration Timed-Endpoint Method. Hyattsville, MD: Centers for Disease Control and Prevention; available at http://www.cdc.gov/nchs/nhanes/ nhanes2005-2006/FETIB_D.htm

23. Collaborative Laboratory Services (2008) Laboratory Procedure Manual: Total Calcium. Hyattsville, MD: Centers for Disease Control and Prevention; available at http://www.cdc.gov/nchs/data/nhanes/nhanes_05_06/ biopro_d_met_calcium.pdf

24. Inorganic Toxicology and Nutrition Branch, Division of Laboratory Sciences, National Center for Environmental Health (2007) Laboratory Procedure Manual: Fat Soluble Micronutrients (Vitamins A, E and Carotenoids) - UV-visible Detection. Hyattsville, MD: Centers for Disease Control and Prevention; available at http://www.cdc.gov/nchs/nhanes/ nhanes2005-2006/VITAEC_D.htm

25. Nutrition Laboratory, Inorganic Toxicology and Nutrition Branch, Division of Laboratory Sciences, National Center for Environmental Health (2007) Laboratory Procedure Manual: Vitamin C. Hyattsville, MD: Centers for Disease Control and Prevention; available at http://www.cdc.gov/ nchs/nhanes/nhanes2005-2006/VIC_D.htm

26. Inorganic Toxicology and Nutrition Branch, Division of Laboratory Sciences, National Center for Environmental Health (2008) Laboratory Procedure Manual for Folatel Vitamin $B_{12}$. Hyattsville, MD: Centers for Disease Control and Prevention; available at http://www.cdc.gov/nchs/ nhanes/nhanes2005-2006/B12_D.htm

27. Agricultural Research Service, Food Surveys Research Group (2008) USDA Food and Nutrient Database for Dietary Studies. Hyattsville, MD: US Department of Agriculture.

28. Manz F \& Wentz A (2005) Hydration status in the United States and Germany. Nutr Rev 63, 6 Pt 2, S55-S62.

29. Popkin BM, D'Anci KE \& Rosenberg IH (2010) Water, hydration, and health. Nutr Rev 68, 439-458.

30. Popkin BM, Barclay DV \& Nielsen SJ (2005) Water and food consumption patterns of US adults from 1999 to 2001. Obes Res 13, 2146-2152.

31. Duffey KJ \& Popkin BM (2006) Adults with healthier dietary patterns have healthier beverage patterns. J Nutr 136, 2901-2907.

32. Panel on Dietetic Products, Nutrition and Allergies (2010) Scientific opinion on Dietary Reference Values for water. EFSA J 8, 1459.

33. Maiani G, Caston MJ, Catasta G et al. (2009) Carotenoids: actual knowledge on food sources, intakes, stability and bioavailability and their protective role in humans. Mol Nutr Food Res 53, Suppl. 2, S194-S218.

34. Byers T (1992) Nutrition monitoring and surveillance. In Nutritional Epidemiology, pp. 347-356 [W Willett, editor]. New York: Oxford University Press. 